\title{
Lung Cancer pT4 TNM Finding v7
}

National Cancer Institute

\section{Source}

National Cancer Institute. Lung Cancer pT 4 TNM Finding V7. NCI Thesaurus. Code C88875.

Lung cancer with a tumor of any size that invades any of the following: mediastinum, heart, great vessels, trachea, recurrent laryngeal nerve, esophagus, vertebral body, carina, and separate tumor nodule(s) in a different ipsilateral lobe. (from AJCC 7th Ed.) 